\title{
Avaliação da estratégia de construção naval canadense no período
}

\author{
2010-20191
}

\section{Evaluation of the Canadian National Shipbuilding Strategy in the 2010-2019 Period}

\author{
Jéssica Pires Barbosa Barreto ${ }^{2}$ \\ Thauan Santos ${ }^{3}$
}

Submetido em 28 de julho de 2020 e aprovado em 14 de fevereiro de 2021.

Resumo: Após grandes cortes na pasta de defesa nos anos 1990, o Canadá se deparou com um cenário de equipamentos obsoletos e redução na sua capacidade militar de atuação, principalmente no início dos anos 2000. Com a chegada de Primeiro-ministro Stephen Harper ao poder (2006 - 2015), essa situação ganha maior atenção do governo. Há diversas iniciativas no âmbito das aquisições de defesa para aprimorar a indústria nacional e capacitar as forças. Um desses projetos foi o lançamento da National Shipbuilding Strategy (2010). Com a finalidade não só de reaparelhar a Marinha e a guarda costeira do país, mas também reestruturar a indústria local e garantir benefícios socioeconômicos para a sua população, essa estratégia é uma das iniciativas mais ambiciosas do governo canadense. Assim, o artigo tem como principal objetivo avaliar essa intervenção a partir de três modelos de avaliação de políticas públicas: modelo orientado a objetivos atingidos, que identifica resultados imediatos, intermediários e finais na política; modelo de efeitos colaterais, identificando como efeito-colateral positivo previsto o aumento da arrecadação de impostos e como negativo previsto o aumento da dependência do setor em relação ao Estado; e o modelo orientado a Stakeholders, que demonstra os principais interessados nesse projeto, tanto no governo quanto na indústria. Para esse fim, serão usadas fontes primárias e secundárias. O resultado preliminar do estudo é positivo em relação à implementação dessa política.

Palavras-chave: National Shipbuilding Strategy. Políticas Públicas. Canadá. Aquisições de Defesa.

\begin{abstract}
After major cuts in the defense sector in the 1990s, Canada faced a scenario of obsolete equipment and a reduction in its military capacity to act, mainly in the early 2000s. With the arrival of Prime Minister Stephen Harper (2006 - 2015), this situation gains greater attention from the government. Thus, there are several initiatives in the scope of defense acquisitions to improve the national industry and empower the forces. One project was the launch of the National Shipbuilding Strategy (2010). With the aim of not only refitting the country's navy and the coast guard, but also restructuring the local industry and ensuring socio-economic benefits for its population, this strategy is one of the most ambitious initiatives by the Canadian government. The article's main objective is to evaluate this intervention based on three models of public policy evaluation: model oriented to achieved objectives, which identify immediate, intermediate and final results
\end{abstract}


in the politics; model of side effects, recognizing as an expected positive side effect the increase in tax collection and as an expected negative increase in the sector's dependence on the State; and the model oriented to Stakeholders, which demonstrate the main actors interested in this project, both in the government and in the industry. For this purpose, primary and secondary sources will be used. The preliminary result of the study is positive regarding the implementation of this policy.

Keywords: National Shipbuilding Strategy. Public Policies. Canada. Defence Procurement.

\section{Introdução}

O Canadá é o segundo maior país em extensão territorial do mundo, localizado entre três oceanos - Ártico, Atlântico e Pacífico - e com a maior linha de costa. Além disso, o país possui a quinta maior zona econômica exclusiva $(\mathrm{ZEE})^{4}$. Assim, o mar é um fator presente na dinâmica canadense, mas nem sempre considerado nas decisões estratégicas do país. Durante muito tempo, o país enxergava os oceanos ao seu redor como um tipo de barreira de proteção natural, um fator que dificultava a invasão de outros Estados, apesar do grande uso dessa via comercial. Mais recentemente, com os desenvolvimentos tecnológicos, o mar se tornou via de ligação.

Historicamente, o Canadá sempre esteve sob a proteção de algum ator proeminente no cenário internacional. Essa condição exerceu influência sobre as decisões do governo quanto a investimentos em defesa e sobre o imaginário de segurança ${ }^{5}$ da população. $\mathrm{O}$ primeiro grande "protetor" do país foi o Reino Unido devido a sua posição como colônia e, posteriormente, como aliado. Essa situação permanece até a Segunda Guerra Mundial (1939-1945), momento em que o país passa a estreitar o seu relacionamento com os Estados Unidos da América (EUA) no âmbito da defesa e segurança.

A fronteira do Canadá com os EUA constitui na maior fronteira terrestre do mundo entre dois únicos países. Apesar dessa proximidade geográfica, os dois viveram períodos de conflito, destacando-se a Guerra de 1812 em que os EUA invadiram o território canadense. Entretanto, há um movimento em busca de maior cooperação e coordenação entre ambos muito motivados pelo conceito de segurança continental e defesa conjunta (BARRETO, 2019). Essa situação aliada a percepção de falta de uma ameaça no sistema fez com que os investimentos na modernização do setor de defesa fossem escassos. Essa 
situação sofria alterações em períodos de conflito internacional, criando um ciclo de gastos militares subindo e, depois, descendo de forma exponencial em períodos de paz.

As demandas de defesa canadenses eram marcadas por instabilidades. Sofrendo com demandas cíclicas - períodos de alta produção durante as duas grandes guerras do século XX e baixas em períodos de paz -, o governo canadense buscou investir no desenvolvimento da indústria naval do país a partir dos anos 1950, dando prioridade para a construção de seus navios no âmbito nacional, visando não só a sua capacidade militar, mas também os benefícios regionais gerados por essa indústria. Entretanto, esse investimento não era contínuo. Por causa da demanda doméstica instável, diversas indústrias que se desenvolveram em momentos de muito investimento não foram capazes de entrar no mercado internacional nos períodos de baixa, fechando ou diminuindo sua capacidade (BARRETO, 2020a).

Desse modo, a indústria naval canadense é marcada por instabilidades em relação à sua demanda e capacidade de produção. Com o fim da Guerra Fria (1945-1991) e os efeitos da crise financeira no país nos anos 1970s e 1980s, os anos 1990s foram marcados por grandes cortes em todas as áreas da administração do país, mas a pasta mais afetada foi a de defesa, assimilando cortes de aproximadamente $30 \%$ do seu orçamento em termos reais (SOLOMON; PENNEY, 2020). Associado a isso, há uma situação de sucateamento das forças armadas, que se mantém até o início dos anos 2000s.

Com a chegada do Primeiro-ministro Stephen Harper ao poder, há um crescimento no debate sobre a situação das forças e sua capacidade de cumprir compromissos, não só com a defesa do país, mas também com seus aliados. Tendo como principal objetivo fornecer os equipamentos adequados para as forças armadas, o governo buscou estabelecer diversas iniciativas na área de aquisições de defesa, tanto através de novos programas de compras de equipamentos, como também implantando mudanças na busca de maior eficiência do sistema de aquisições em si. Uma das principais iniciativas desse movimento foi o lançamento da National Shipbuilding Strategy (NSS), em 2010, que tem como objetivo não só o reaparelhamento da marinha canadense, mas também a reestruturação da indústria naval do país e a geração e manutenção de empregos. 
Nesse sentido, o objetivo principal do artigo desenvolvido é analisar, dentro do âmbito de avaliações de políticas públicas, a NSS, seus objetivos e resultados. Para esse fim, a pesquisa se utilizará de fontes primárias e secundárias para construir a avaliação do caso. O trabalho será dividido em três partes, além dessa introdução: uma sessão histórica, identificando as circunstâncias nas quais a NSS foi lançada e o ambiente em que ele se inseriu; uma sessão de avaliação da política, que utilizará três modelos - o modelo orientado a objetivos atingidos, o modelo de efeitos colaterais e o modelo orientado a Stakeholders - e uma última sessão com considerações finais do estudo.

\section{National Shipbuilding Strategy (NSS)}

Ainda que a partir dos anos 1950s o Canadá tenha priorizado a construção de suas embarcações nacionalmente, historicamente, a indústria naval canadense enfrenta muita instabilidade nas suas demandas. Com decisões essencialmente políticas, graças aos altos custos dos projetos e a falta de apoio da sociedade quanto a esses gastos, o governo tem dificuldades em manter projetos consecutivos, fazendo com que muitas empresas que não conseguiram se inserir no mercado internacional fechassem ou reduzissem sua infraestrutura, com grandes perdas de conhecimento na área (WILSON, 2009).

Assim, apesar de possuir uma enorme extensão territorial, o Canadá tem capacidade material limitada, em decorrência da instabilidade das demandas e da politização dos seus investimentos na área. Principalmente por causa dessa limitação, o país buscou se definir como "potência média" em seus documentos oficiais, buscando o reconhecimento dessa imagem no cenário internacional e a garantia de certa capacidade de influência, principalmente através dos organismos internacionais de cooperação. A sua participação enfática em operações de paz, principalmente, a partir dos anos 1950s ilustra essa busca (ALBUQUERQUE; BARRETO, 2019).

Como pode-se observar no Gráf. I, os mais altos índices nos gastos com defesa no Canadá coincidem com os momentos em que seus documentos de defesa apresentavam as maiores ameaças, ainda que não fossem ameaças diretas ao país, como aconteceu durante o início da Guerra Fria. Nesse período, sentia-se ameaçado por causa da sua geografia, pois acreditavam que um ataque aos EUA vindo da União das Repúblicas 
Socialistas Soviéticas (URSS) afetaria o seu território devido à proximidade dos países (CANADA, 1964).

Percebe-se que os gastos do país foram mais altos durante os anos mais apreensivos da Guerra Fria; entretanto, com o fim da sensação de ameaça por parte de sua população e de seus governantes e havendo grande pressão da sociedade para investimentos em outras áreas, cortes massivos diminuíram a pasta de defesa, levando ao sucateamento dos seus equipamentos militares e grande abandono da sua indústria de defesa. A década de 1990 foi o período em que o país seguiu a tendência mundial de cortes nos gastos militares por pressões domésticas visto que não havia mais uma ameaça no cenário internacional.

Graf. I - Gastos militares canadenses no período 1960-2019 (\% PIB)

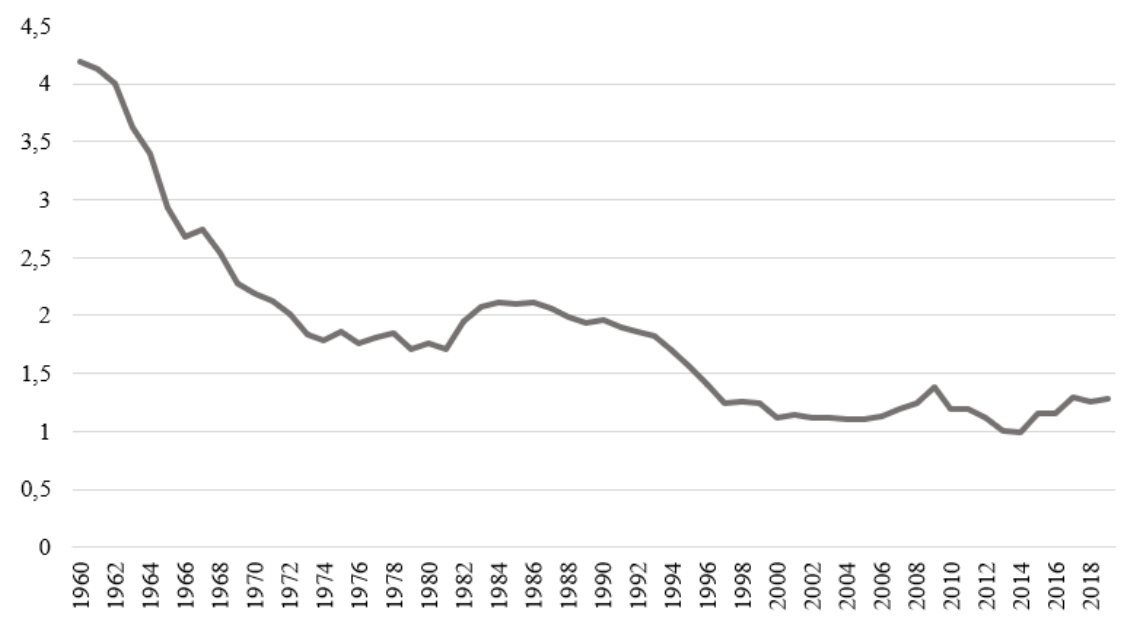

Fonte: elaboração própria com base no banco de dados do SIPRI.

Disponível em: https://www.sipri.org/databases/milex. Acesso em: 20 fev. 2020.

Foi só a partir do final de 2001, com o atentado ao EUA e a queda das Torres Gêmeas, que se começou uma tentativa no país de maiores investimentos militares por causa da sua participação em diversas operações, com especial destaque a sua presença no Afeganistão, mas sem grandes variações. A continuidade dos seus gastos, apesar do cenário internacional, deve-se, principalmente, há sensação de segurança da sociedade 
canadense, muitas vezes não aprovando o aumento de gastos em defesa para o seu envolvimento nessas ações no exterior.

Em 2006, o partido conservador de Stephen Harper chegou ao poder trazendo uma forte pauta relacionada ao sucateamento dos equipamentos das forças armadas e a necessidade de maior atenção a esse segmento. Ele defendeu durante o período eleitoral que as forças canadenses estavam lidando com equipamentos ultrapassados e dificuldades de manter seus compromissos no cenário internacional, como operações da Organização do Tratado do Atlântico Norte (OTAN) e exercícios militares com aliados. Desse modo, era necessário um novo planejamento de investimentos e reestruturação militar.

Esse discurso não foi novidade no pós-2001. O governo liberal de Paul Martin enxergava a mesma necessidade do reaparelhamento militar, inclusive focando na necessidade de substituição dos Navios auxiliares da Marinha canadense. Essa necessidade era debatida no governo desde os anos 1990s, obtendo pouco apoio no âmbito do executivo. Assim, esse governo lança o projeto dos Joint Support Ships (JSS), que foi cancelado para posterior revisão no início do governo Harper (WILSON, 2009).

A política de defesa lançada em 2008 trouxe ênfase na vontade de modernizar as forças armadas, garantindo equipamentos altamente tecnológicos e necessários para o cumprimento de seus objetivos no meio internacional. O documento trazia a ideia de um plano de modernização a longo prazo de todos os pilares da força, incluindo pessoal e infraestrutura. Desse modo, alguns dos objetivos eram aumentar o número de combatentes nas forças armadas e adquirir 15 embarcações para substituir as fragatas e destroiers em serviço (CANADA, 2008).

Apesar de ter determinado a necessidade de investimento e associar esses gastos em defesa com a possibilidade de benefícios econômicos para a sociedade, o documento não foi tão claro sobre como se dariam esses investimentos ao longo dos anos, apresentando valores exorbitantes e sendo pouco específico quanto aos projetos de aquisição (Idem). Um dos primeiros movimentos do governo foi a volta do projeto de construção dos JSS, que havia sido cancelado no início do seu governo, mas o programa atingiu valores altíssimos em pouco tempo e foi novamente cancelado, levando o governo a pedir uma revisão sobre todo o processo desde o governo anterior para uma comissão representada 
por diferentes órgãos do governo para entender os problemas dentro das aquisições, em especial no setor naval (COLLINS, 2019).

O resultado desse processo foi uma recomendação sugerindo que observar apenas a necessidade de reaparelhamento das forças armadas não era o suficiente para garantir uma aquisição dentro do cronograma e do orçamento adequado; uma reestruturação da indústria naval do país também era necessária, além de garantia de previsibilidade dos investimentos a partir do governo (BARRETO, 2020a). Assim, em 2010, foi lançada oficialmente a "National Shipbuilding Strategy" (NSS), uma estratégia de construção naval ambiciosa que tem como objetivo modernizar a marinha e a guarda-costeira num período de até 30 anos, representando um esforço do governo para reaparelhar sua força armada e garantir uma demanda contínua para a indústria nacional (SHOUTE, 2015).

As conversas sobre a necessidade de investimento na construção naval do país já aconteciam durante o governo Chrétien (1993-2003); entretanto, o foco ainda eram os projetos únicos. Foi apenas com o fracasso do programa de construção dos JSS (2008) que se viu a necessidade de uma nova abordagem para essas aquisições (COLLINS, 2019). Ademais, uma grande influência para a elaboração e lançamento da NSS foi o ministro de defesa da época Peter Mackay, que representava interesses de empresas do ramo de construção naval da província de Nova Scotia (WILSON, 2009). Assim, a NSS é a maior política de modernização a longo prazo da Marinha em períodos de paz da história canadense, visando não só o reaparelhamento das forças armadas, mas também a criação de empregos e a competitividade da indústria nacional (AUGER, 2015).

O plano previa a construção de embarcações para a guarda-costeira e a Royal Canadian Navy (RCN) divididos em dois componentes: a construção de grandes embarcações e a de pequenas embarcações. Um terceiro componente da estratégia é o de manutenção e reparo (SHOUTE, 2015). O componente envolvendo a construção dos grandes navios, por ser extremamente caro e longo, foi dividido em dois pacotes de construção - o pacote de combatentes e o de não-combatentes -, e teve sua implementação dividida em cinco fases, como pode-se observar na Fig. I. A primeira fase foi o próprio desenvolvimento da estratégia enquanto a segunda foi a seleção dos estaleiros responsáveis pelas construções. Essas duas fases envolveram diversas conversas com a indústria para 
entender as limitações e expectativas dos dois atores, o que foi uma grande mudança em relação a como o governo procedia com seu ciclo de aquisições (CANADA, 2017a).

Fig. I - Fases de implementação do Componente de construção de grandes embarcações

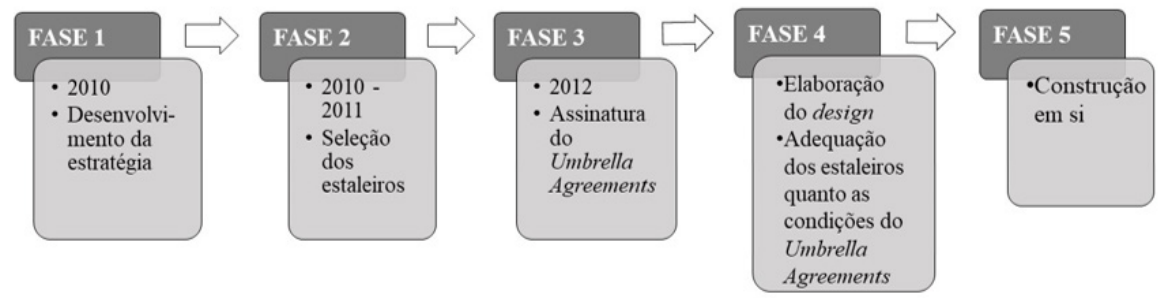

Fonte: BARRETO, 2020a, p. 53.

A segunda fase começou no final de 2010, com uma solicitação de interesse ${ }^{6}$ (SOI) lançada pelo governo que resultou na pré-seleção de cinco estaleiros. Já em 2011, o governo divulgou uma solicitação de proposta $^{7}$ (RFP), em que os estaleiros que haviam sido pré-selecionados anteriormente deveriam enviar ao governo suas propostas para os pacotes (SHOUTE, 2015). Ao final de cinco meses, apenas três dessas empresas enviaram suas propostas e foram escolhidos o Irving Shipbuilding's Halifax Shipyard, responsável pelo pacote de construção dos navios de combate, e o Seaspan's Vancouver Shipyards, responsável pelo pacote de construção das embarcações de não-combate (CANADA, 2017a). Em 2019, o governo anunciou uma expansão da estratégia, aumentando o número de algumas embarcações que já estavam previstas e investindo na parceria com um terceiro estaleiro, principalmente para a construção de quebra-gelos (CANADA, 2019a).

O governo lançou em agosto de 2019 um processo para a pré-seleção desse terceiro estaleiro. A competição terminou em dezembro com o anuncio de que o Chantier Davie, localizado em Quebec, havia sido selecionado. Após esse momento, o estaleiro teve um período de entrega do seu RFP e a avaliação do governo. Há a expectativa de que o processo seja finalizado até o final de 2020 com o estabelecimento da relação estratégica entre o governo e essa empresa como foi realizado com os outros dois estaleiros (CANADA, 2020). 
A terceira fase da implantação do componente consistia na assinatura de um acordo entre as partes que não garantia aos estaleiros a construção dessas embarcações, mas estabelecia os deveres dos estaleiros e do governo com o objetivo de criar um vínculo de confiança entre o poder público e essas empresas através do "Umbrella Agreements" (2012). As condições para os estaleiros conseguirem os contratos envolviam altos investimentos no preparo do pessoal e expansão da infraestrutura (AUGER, 2015), que seriam supervisionadas por um terceiro agente - First Marine International - constituído por especialistas da área e imparcial no processo para garantir maior transparência (BOWERING, 2012). A quarta fase consistiu no desenvolvimento do design e adaptação dos estaleiros às condições do "Umbrella Agreements" enquanto a última é a construção dos navios em si (CANADA, 2017a).

Enquanto os projetos de grandes navios são de responsabilidade de dois estaleiros, cada projeto do componente de pequenas embarcações é concedido através de uma competição, entretanto os estaleiros Irving e Seaspan não poderiam participar. Assim, os benefícios dos programas de construção naval não ficariam concentrados em poucos. Um dos objetivos da estratégia é diversificar os benefícios socioeconômicos e atingir, principalmente, pequenas e médias empresas, que são maioria na base industrial de defesa do país. A concessão dos projetos do componente de reparo e manutenção é feita através de competição aberta para todos (AUGER, 2015).

Ademais, para suporte da NSS foi criada uma secretaria de gerenciamento com representação do Departamento de Serviços Públicos e Compras do Canadá (PSPC), do Departamento de Defesa Nacional do país (DND), do Departamento de Inovação, Ciência e Desenvolvimento Econômico (ISED) e do Departamento de oceanos e pesca. Tendo sido criado ainda em 2010, a secretaria responde à liderança do PSPC, mas o gerenciamento individual de cada projeto é responsabilidade de escritórios específicos coordenados pelo DND (Idem).

Outro ponto importante são as obrigações de compensação tecnológica envolvidas nos contratos de todos os projetos de defesa do Canadá. Sendo delimitadas pela Política de Benefícios industriais e tecnológicos (ITB), essa compensação é administrada pelo ISED e devem ser investimentos de $100 \%$ do valor do contrato dentro do Canadá. Entretanto, 
os investimentos em áreas prioritárias, como construção naval e inteligência artificial, garantem modificações no valor absoluto que deve ser investido graças a multiplicadores (SHOUTE, 2015).

Uma das maiores dificuldades da implementação da NSS foi o próprio Sistema de Aquisições de Defesa (SAD) do Canadá, que é extremamente burocrático. Isso faz com que o processo seja longo e custoso. O SAD Canadense é caracterizado por ser multidepartamental, ou seja, há três departamentos e uma secretaria diretamente envolvidos nas aquisições da pasta, como mostra a Fig. II, não havendo exatamente uma hierarquia entre eles (AUGER, 2016). Outros agentes também podem ser envolvidos no processo dependendo da necessidade, como o Tribunal Internacional do Comércio do Canadá (CITT, sigla em inglês). Entretanto, a participação de tantos agentes num mesmo processo faz com que não haja um ator a quem responsabilizar.

Fig. II - Agências envolvidas no Sistema de Aquisição de Defesa Canadense

\section{Public Services and Autoridade Contratual \\ Procurement (PSPC) • Responsável por todas as aquisições governamentais}

Department of

National Defence - Desenvolvimento e definição do projeto (DND)

\section{Innovation, Science \\ and Economic Gerenciamento dos beneficios industriais Development (ISED)}

\section{Treasury Board}

Secretariat

- Aprovação do Financiamento

Fonte: elaboração própria.

O PSPC é o departamento responsável por todas as aquisições do governo canadense, sendo ele o ator que emite as SOI e RFP, e um dos responsáveis pelas negociações contratuais. O DND é o cliente nas aquisições de defesa, participando 
do desenvolvimento do projeto, das especificações do produto desejado e da fase de implementação em si. Já o ISED é a agência responsável pela negociação e gerenciamento dos benefícios da ITB e o Treasury Board é a secretaria financeira que aprova todos os orçamentos, diversas vezes ao longo das fases de aquisição, de todos os projetos e seus respectivos contratos. Após todas as negociações, os contratos só podem ser assinados se o Treasury Board der o consentimento final (PLAMONDON, 2010).

A necessidade de negociação e aprovação de tantos agentes em todas as fases do projeto faz com que o processo de aquisição demore para ser posto em prática, além de torná-lo caro. Outro problema histórico no SAD Canadense é a politização das aquisições. Devido à necessidade do governo de aprovação da sociedade, muitos utilizam essas dinâmicas como plataforma política, muitas vezes cancelando projetos que já estão em curso, como aconteceu com o "New Shipborne Aircraft program" (EH101) no governo de Jean Chrétien e o "F-35 program" no governo de Justin Trudeau (NOSSAL, 2016). Assim, há o temor do cancelamento da estratégia de aquisição naval com a chegada de um novo governo, como já aconteceu em momentos da história dessa indústria.

Outros desafios na implementação dessa estratégia foram a incapacidade de calcular com precisão os custos do projeto e a falta de capacidade na produção dos estaleiros. $\mathrm{O}$ primeiro problema é, em grande parte, devido à perda de conhecimento dentro do DND, por causa dos grandes cortes nos anos 1990s. Essa diminuição do orçamento na pasta levou a uma redução de pessoal e, com isso, perda de conhecimento quanto a esses tipos de aquisições complexas. Já a falta de capacidade e conhecimento dos estaleiros é por causa das demandas instáveis do governo, que prejudicaram a curva de conhecimento das empresas e sua infraestrutura (COLLINS, 2019).

\section{Avaliação}

A avaliação de políticas públicas permite, através de um retrospecto, observar e determinar o valor das intervenções do governo, identificando desafios pelos quais a implementação dessa política passou, além de avaliar se ela foi eficiente ou não em resolver o problema e se há necessidade de adaptações da mesma (VEDUNG, 2013). Para a avaliação da NSS serão utilizados três modelos que se complementam: o modelo 
orientado a objetivos atingidos (“Goal-Attainment"), modelo de efeitos colaterais ("SideEffects") e o modelo orientado a Stakeholders. Apesar da NSS ainda estar em curso, a avaliação parcial realizada nesse artigo será referente ao que já foi realizado até o momento (2010-2019).

\subsection{Modelo de avaliação orientado a objetivos atingidos}

O modelo de avaliação orientado a objetivos atingidos (“Goal-Attainment”) busca identificar se os objetivos determinados na política foram alcançados na prática, além de observar se esses resultados são realmente originados pela intervenção do governo ou não. Assim, primeiro deve-se distinguir o que motivou a intervenção e os objetivos que ela assume para, a partir daí, apontar se os mesmos foram alcançados e em que medida a política colaborou ou dificultou esses resultados (VEDUNG, 2013).

A NSS apresenta três grandes objetivos: o reaparelhamento da marinha e da guarda costeira; a reestruturação e manutenção da competitividade da indústria naval, impedindo os ciclos de instabilidade da demanda; e a geração de benefícios econômicos para a sociedade, principalmente em relação a manutenção de empregos (CANADA, 2010). A principal motivação para essa intervenção foi a necessidade de criação de uma demanda previsível e estável que fosse capaz de dar suporte à indústria do país; assim, o governo usou de instrumentos para garantir o seu sucesso, como o estabelecimento de um novo modelo para lidar com essas aquisições através do "umbrella agreements" (AUGER, 2015).

O projeto inicial previa a construção de 38 embarcações no componente de grandes navios e 116 no de pequenos no período de até 30 anos (Idem). Assim, segundo dados da agência de estatísticas do Canadá, antes da NSS a indústria naval fornecia 6813 empregos e tinha uma receita anual de \$1,1 bilhão (CANADA, 2019b). Entendendo que as primeiras fases da implementação da NSS foram voltadas para definição dos projetos e dos estaleiros responsáveis, não havia muitas estimativas em relação a valores. A partir de 2013, com a escolha dos estaleiros para construção do pacote de grandes embarcações, previsões sobre o valor das aquisições começaram a ser estabelecidos, como mostra a tab. I. 
Tab. I - Orçamento dos projetos do componente de grandes embarcações da NSS (C\$ $\left.{ }^{v}\right)$

\begin{tabular}{|c|c|c|c|c|c|c|c|}
\hline PROJETOS & 2010 & 2013 & 2014 & 2015 & 2017 & 2018 & 2019 \\
\hline $\begin{array}{l}\text { Pacote de } \\
\text { Combate }\end{array}$ & $\$ 28,5 \mathrm{~b}$ & \$ 29,3 b & $\$ 29,7$ b & $\$ 29,7$ b & $\begin{array}{c}\$ 59,5 \mathrm{~b}- \\
\$ 63,5 \mathrm{~b}\end{array}$ & $\begin{array}{c}\$ 60,3 \mathrm{~b}- \\
\$ 64,3 \mathrm{~b}\end{array}$ & $\begin{array}{l}\$ 60,3 \mathrm{~b}- \\
\$ 64,3 \mathrm{~b}\end{array}$ \\
\hline AOPS & $\$ 2,3 \mathrm{~b}$ & $\$ 3,1 \mathrm{~b}$ & $\$ 3,5 \mathrm{~b}$ & $\$ 3,5 \mathrm{~b}$ & $\$ 3,5 \mathrm{~b}$ & $\$ 4,3 \mathrm{~b}$ & $\$ 4,3 \mathrm{~b}$ \\
\hline $\mathrm{CSC}$ & $\$ 26,2 \mathrm{~b}$ & $\$ 26,2 \mathrm{~b}$ & $\$ 26,2 \mathrm{~b}$ & $\$ 26,2 \mathrm{~b}$ & $\begin{array}{c}\$ 56 \mathrm{~b}-\$ \\
60 \mathrm{~b}\end{array}$ & $\begin{array}{c}\$ 56 \mathrm{~b}-\$ \\
60 \mathrm{~b}\end{array}$ & $\begin{array}{c}\$ 56 \mathrm{~b}-\$ \\
60 \mathrm{~b}\end{array}$ \\
\hline $\begin{array}{l}\text { Pacote de } \\
\text { Não-combate }\end{array}$ & $\$ 3,78 \mathrm{~b}$ & $\$ 4,3 \mathrm{~b}$ & $\$ 4,64 \mathrm{~b}$ & $\$ 4,73 \mathrm{~b}$ & $\$ 5,9 \mathrm{~b}$ & $\$ 5,9 \mathrm{~b}$ & $\$ 6,4 \mathrm{~b}$ \\
\hline JSS & $\$ 2,6 \mathrm{~b}$ & $\$ 2,6 \mathrm{~b}$ & $\$ 2,6 \mathrm{~b}$ & $\$ 2,6 \mathrm{~b}$ & $\$ 3,4 \mathrm{~b}$ & $\$ 3,4 \mathrm{~b}$ & $\$ 4,1 \mathrm{~b}$ \\
\hline OFSV & $\$ 244 \mathrm{~m}$ & $\$ 244 \mathrm{~m}$ & $\$ 594 \mathrm{~m}$ & $\$ 687 \mathrm{~m}$ & $\$ 687 \mathrm{~m}$ & $\$ 687 \mathrm{~m}$ & $\$ 687 \mathrm{~m}$ \\
\hline OOSV & $\begin{array}{c}\$ 144,4 \\
\mathrm{~m}\end{array}$ & $\begin{array}{c}\$ 144,4 \\
\mathrm{~m}\end{array}$ & $\$ 144,4 \mathrm{~m}$ & $\$ 144,4 \mathrm{~m}$ & $\$ 331 \mathrm{~m}$ & $\$ 331 \mathrm{~m}$ & $\$ 331 \mathrm{~m}$ \\
\hline Quebra-gelo & $\$ 0,8 \mathrm{~b}$ & $\$ 1,3 \mathrm{~b}$ & $\$ 1,3 \mathrm{~b}$ & $\$ 1,3 \mathrm{~b}$ & $\$ 1,3 b$ & $\$ 1,3 \mathrm{~b}$ & $\$ 1,3 \mathrm{~b}$ \\
\hline
\end{tabular}

Fonte: elaboração própria com base em BARRETO, 2020a, p. 77.

Tendo em mente os três objetivos que norteiam a NSS, podemos identificar alguns resultados, como apontado na Fig. III. Em relação ao objetivo de reestruturação da indústria naval, percebe-se que, no período entre 2012-2015, os estaleiros Irving e Seaspan investiram em torno de \$500 milhões para modernizar sua infraestrutura (CANADA, 2016). Já dentro do objetivo de reaparelhamento da marinha e da guarda costeira, o estaleiro Irving entregou à marinha o primeiro "Artic Offshore Patrol Ship" em 2018. 
Fig. III - Modelo de avaliação orientado a objetivos atingidos do NSS

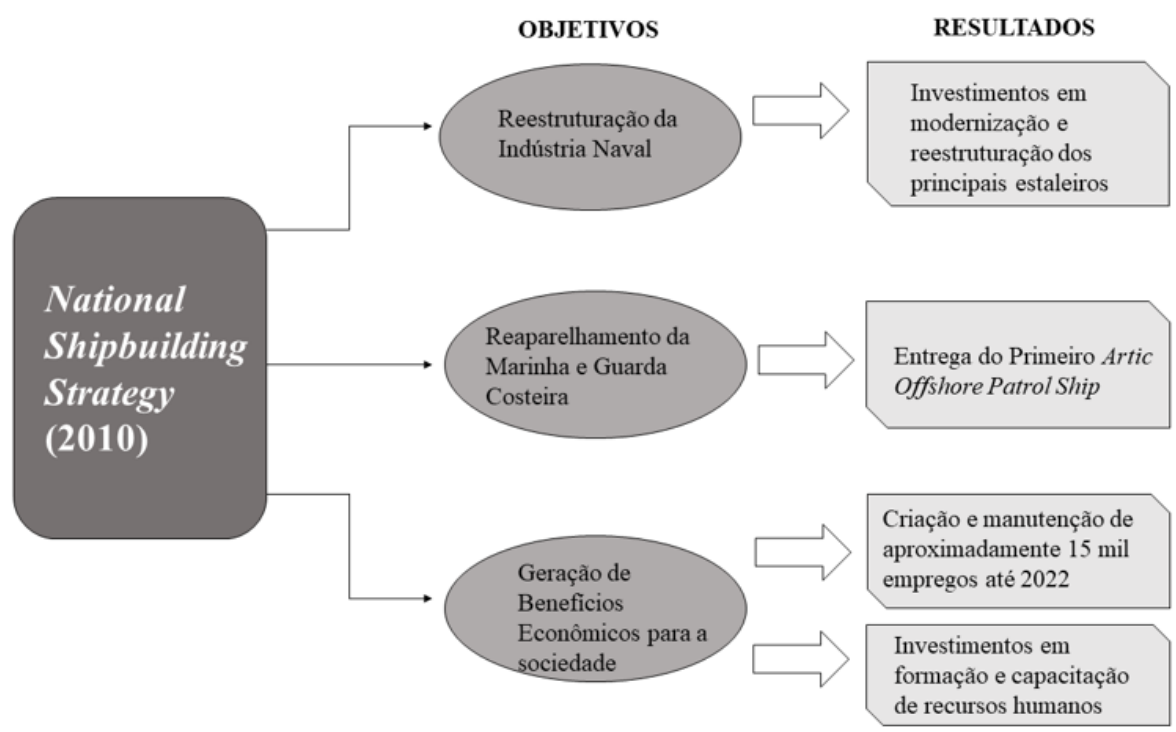

Fonte: elaboração própria.

Dentro do objetivo de geração e manutenção de empregos, como podemos observar na tab. II, os relatórios do governo mostram que os contratos concedidos em 2017 criaram ou mantiveram em torno de 2374 empregos anuais entre 2017-2022 (CANADA, 2018), os contratos concedidos em 2018 criaram ou mantiveram em torno de 2987 empregos anuais entre 2018-2022 (CANADA, 2019c), e aqueles concedidos em 2019 vão gerar ou manter 3162 empregos anuais entre 2019-2022 (CANADA, 2020). Além disso, relatórios independentes mostram que a construção dos AOPS tem gerado em torno de 4230 empregos por ano entre 2016-2020 (THE CONFERENCE BOARD OF CANADA, 2018). 
Tab. II - Contratos concedidos e empregos gerados ou mantidos pela NSS

\begin{tabular}{|c|c|c|}
\hline $\begin{array}{c}\text { ANOS DOS } \\
\text { RELATÓRIOS }\end{array}$ & $\begin{array}{c}\text { CONTRATOS } \\
\text { CONCEDIDOS (CS } \\
\text { bilhão) }\end{array}$ & EMPREGOS (2012-2022) \\
\hline 2012-2015 & 1,3 & 5500 \\
\hline 2016 & 0,47 & 7350 \\
\hline 2017 & 1,3 & 8788 \\
\hline 2018 & 1,8 & 10190 \\
\hline 2019 & 3,3 & 10365 \\
\hline
\end{tabular}

Fonte: elaboração própria.

A avaliação parcial aqui desenvolvida observa que, em primeiro lugar, os resultados encontrados e aqui apontados foram fruto direto da intervenção do Estado e todos possuem correlação, visto que não seria possível o aumento do número de empregos se não houvesse maior investimento dos estaleiros e garantia de demanda estável. Desse modo, de acordo com os resultados encontrados, os objetivos estabelecidos pela estratégia de construção naval estão sendo alcançados, apesar de alguns atrasos nos cronogramas estabelecidos no início dos projetos. Apesar disso, esse processo apresentou, até o momento, efeitos colaterais, tanto positivos quanto negativos, que devem ser melhor analisados.

\subsection{Modelo de avaliação de Efeitos Colaterais}

O modelo de avaliação de efeitos colaterais traz a ideia de que a política pública também pode ter resultados fora da área a que ela se destina originalmente, ou seja, ela produz resultados que não são planejados junto com a intervenção e não são englobadas pelos seus objetivos. Assim, esses subprodutos podem ser previstos ou não-previstos, positivos e negativos. Desse modo, é importante identificar esses efeitos para adaptações ou o planejamento de novas intervenções (VEDUNG, 2013).

Para a melhor compreensão da análise, os efeitos foram divididos entre positivos previsto, positivos não-previstos, negativos previstos e negativos não-previstos, como 
mostra a Fig. IV. Os efeitos positivos previstos encontrados no caso foram o impacto no PIB e o aumento na arrecadação de impostos. Esses efeitos são consequência do aumento de investimentos na região, criação de empregos e as compras em si, que geram demandas para o funcionamento dos estaleiros.

Em especial, o impacto no PIB é amplamente divulgado pelos relatórios do governo como um dos benefícios que resultaram dessa estratégia, apesar de não ter sido o objetivo central da mesma. É mostrado no relatório referente ao ano de 2016 o impacto total dos contratos de construção naval sendo de \$7,7 bilhões entre 2012-2022 (CANADA, 2017b). No relatório respectivo ao ano de 2017 , é apresentado um impacto total de $\$ 8,9$ bilhões entre 2012-2022 (CANADA, 2018). Já no relatório anual de 2018, esse impacto total da estratégia entre 2012-2022 é de \$10,9 bilhões (CANADA, 2019c). No último relatório divulgado pelo governo, é observado um impacto total de \$ 4,1 bilhões entre 2019-2022 (CANADA, 2020). Esses valores vão sendo alterados de acordo com os contratos de construção assinados no período.

Fig. IV - Modelo de avaliação de efeitos colaterais do NSS

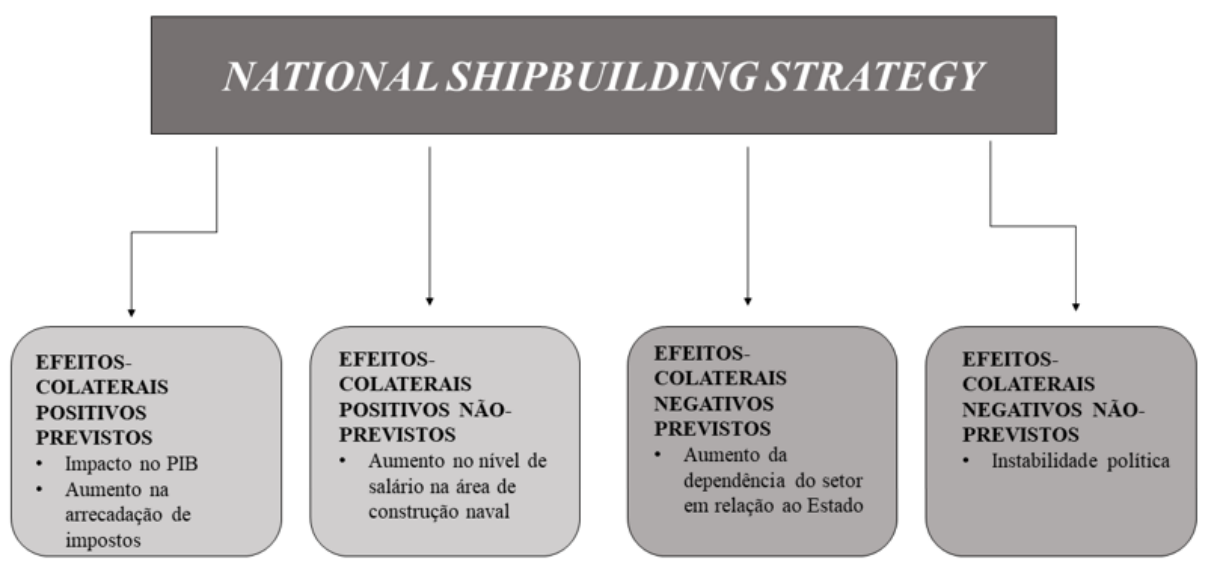

Fonte: elaboração própria. 
O efeito colateral positivo não-previsto identificado foi o aumento no nível salarial na área de construção naval no período da estratégia. Os relatórios anuais em relação ao ano de 2018 e 2019 mostram que o salário na área de construção naval está 30\% maior do que outros setores de manufatura (CANADA, 2019c; CANADA, 2020). Um dos principais motivos disso é o investimento em infraestrutura, que exigem profissionais bem-qualificados, além da necessidade desses profissionais para atender às demandas do governo. Uma das exigências da política ITB é o investimento na qualificação da mão-de-obra.

O efeito colateral negativo previsto é o aumento da dependência do setor em relação ao Estado. Historicamente, o setor tem tido problemas de se manter sem incentivos governamentais e uma demanda contínua, com muitas empresas fechando em períodos de poucas compras (WILSON, 2009), entretanto, com a estratégia, diversas empresas adaptaram sua infraestrutura e mão-de-obra para responder às aquisições do governo e, sem essa demanda efetiva, não conseguirão se inserir no mercado internacional. Assim, a estratégia aprofunda essa relação de dependência.

Por último, o efeito colateral negativo não-previsto é a instabilidade política. Apesar dos benefícios econômicos que essa estratégia tem gerado para o país, algumas províncias, em especial Alberta, não se sentem comtempladas pelos investimentos feitos. O argumento é de que os investimentos e os benefícios gerados por eles são concentrados nas regiões em que essa infraestrutura de construção naval está inserida, em especial Ontario, Nova Scotia e a Columbia Britânica. Assim, a insatisfação tem aumentado o percentual de rejeição do governo, além de ter custado alguns assentos ao partido liberal nas últimas eleições parlamentares, em outubro de 2019.

Percebe-se como a identificação dos efeitos colaterais da NSS é importante para complementar a análise como um todo. Não é suficiente identificar o que está previsto na estratégia, mas também o que não estava previsto, porém ocorre na realidade. Isso colabora para possíveis adaptações dessa intervenção ou uma nova política voltada para esses efeitos adversos. Além dos dois modelos já analisados, faz-se necessário uma observação dos atores envolvidos nessa intervenção para identificar possíveis interesses e as motivações da mesma. 


\subsection{Modelo de avaliação orientado a Stakeholders}

O modelo de avaliação orientado a stakeholders identifica e analisa os atores interessados, envolvidos e afetados pelas intervenções governamentais. Algumas formas de distinguir esses agentes são através da identificação de quem está financiando as políticas, quem está à frente de sua implementação e quem será direta ou indiretamente afetado por ela, tanto positiva quando negativamente (VEDUNG, 2013).

Para efeitos de análise, dividiu-se os stakeholders em duas categorias, como mostrado na Fig. V, sendo elas governo e indústria. Os atores envolvidos na estratégia de construção naval são o DND, o PSPC, o ISED e o Treasury Board, visto que são os agentes responsáveis pelo desenvolvimento e definição do projeto e sua implementação. Além disso, temos a RCN e a Guarda Costeira como as principais interessadas no projeto para seu reaparelhamento.

Fig. V - Modelo de avaliação orientado a Stakeholders do NSS
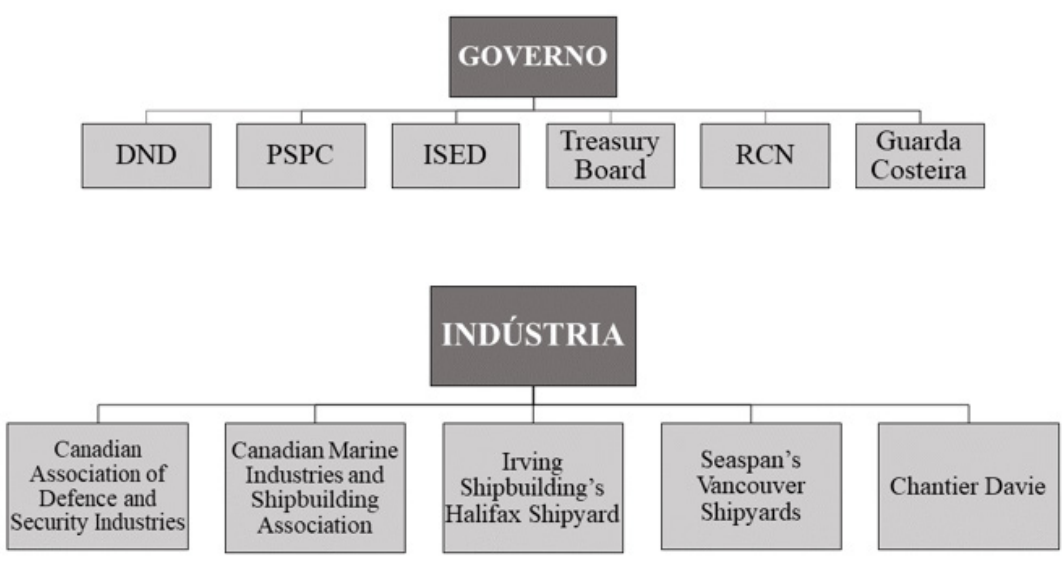

Fonte: elaboração própria.

No âmbito da indústria, identificamos como principais interessados a Canadian Association of Defence and Security Industries (CADSI), a Canadian Marine Industries and Shipbuilding Association (CMISA) e os estaleiros Irving, Seaspan e Chantier Davie. 
Somente esses três estaleiros foram destacados visto que são os maiores do país e os que enviaram propostas para o projeto de construção de grandes navios. Assim, eles também seriam os principais beneficiados pelos investimentos previstos na estratégia.

As associações foram destacadas por serem as representantes desse setor frente ao governo quando há consultas para o desenvolvimento e definição da estratégia, principalmente das pequenas e médias empresas que têm sido amplamente beneficiadas pelos projetos de construção de pequenas embarcações e como fornecedores dos grandes estaleiros. O relatório referente ao ano de 2019 mostra que em torno de 780 empresas de pequeno e médio porte tiveram acesso a oportunidades da NSS (CANADA, 2020) através dos grandes estaleiros ou com o auxílio das associações na preparação de suas propostas para projetos menores.

\section{Considerações Finais}

O setor de construção naval foi importante para o desenvolvimento industrial de algumas províncias canadenses, além de ter tido destaque em momentos históricos do país quando envolvido em conflitos. Apesar disso, a sua principal característica são os ciclos de demanda, tendo momentos de muitas compras e grande desenvolvimento e outros momentos de queda na demanda e perda de capacidade. Essa situação afetava diretamente a curva de conhecimento das empresas envolvidas nessa área e a sua capacidade de produção. A introdução da NSS tem como principal intuito acabar com essa instabilidade, mas muitas dificuldades na sua implementação derivam dessa condição passada de altas e baixas.

Compreender a implementação da NSS e o ambiente estratégico em que ela se insere é necessário para qualquer país que deseje realizar negócios e aproveitar oportunidades no Canadá. No caso brasileiro, é interessante que a situação dos submarinos classe-Victoria seja observada, visto que o Brasil tem desenvolvido e se especializado na construção de embarcações desse tipo. O artigo teve como principal objetivo mostrar como tem sido implementada a estratégia de construção naval canadense, avaliando sua eficácia até o momento através de diferentes modelos da teoria de avaliação de políticas públicas. 
O desenvolvimento do trabalho evidenciou que o uso de um único modelo de avaliação pode gerar uma análise incompleta e tendenciosa, sendo necessário o complemento de outras variáveis para se compreender todo o cenário em que a estratégia está inserida e os efeitos produzidos, tanto em relação aos seus objetivos quanto àqueles não planejados pelo governo. A NSS enfrentou dificuldades, principalmente nos primeiros anos de implementação, por causa da falta de capacidade da indústria, pouca infraestrutura desenvolvida e falta de recursos humanos envolvidos no desenvolvimento dos projetos de aquisição que tivessem o know-how desse processo burocrático. Além disso, o governo também enfrentou problemas inerentes ao sistema de aquisição de defesa do país. Dessa forma, tiveram que lidar com atrasos nos projetos, e problemas na estimativa de orçamento inicial e na capacidade dos estaleiros.

Apesar disso, tendo em mente os três principais objetivos da estratégia - o reaparelhamento da marinha e da guarda costeira; a reestruturação e manutenção da competitividade da indústria naval, impedindo os ciclos de instabilidade da demanda; e a geração de benefícios econômicos e sociais para a sociedade, principalmente através da geração e manutenção de empregos - foi identificado que as ações do governo tem colaborado para a consecução de todos eles. Através dos três modelos aqui aplicados, percebe-se uma avaliação parcial positiva em relação à política implementada pelo Estado canadense.

\section{Referências}

ALBUQUERQUE, Beatriz Martins de; BARRETO, Jéssica Pires Barbosa. Os diferentes Interesses nas Operações de Paz: casos Canadense e Brasileiro. Conjuntura Internacional, v. 16, n. 1, 2019, p. 10-17. Disponível em: http://periodicos.pucminas.br/index.php/ conjuntura/article/download/18808/15108/. Acesso em: 23 mai. 2020.

AUGER, Martin. The National Shipbuilding Procurement Strategy: A Five-year Assessment. Ottawa: Library of Parliament, 2015. Disponível em: https://lop.parl.ca/ staticfiles/PublicWebsite/Home/ResearchPublications/BackgroundPapers/PDF/201535-e.pdf. Acesso em: 04 jul. 2020.

AUGER, Martin. The Evolution of Defence Procurement in Canada. Ottawa: Library of Parliament, Background Paper, 2016. Disponível em: https:/lop.parl.ca/sites/ PublicWebsite/default/en_CA/ResearchPublications/201535E. Acesso em: 20 jun. 2020. 
BARRETO, Jéssica Pires Barbosa. A Influência dos Acordos de Defesa Conjunta na Indústria Canadense. In: III ENCONTRO REGIONAL DAASSOCIAÇÃO BRASILEIRA DE ESTUDOS DE DEFESA (ERABED) - SUDESTE, 2019. Disponível em: https:// www.erabedsudeste2019.abedef.org/resources/anais/12/erabedsudeste2019/157149936 8_ARQUIVO_9a8a8aac551a43443276483b3a1601a7.pdf. Acesso em: 20 jun. 2020.

BARRETO, Jéssica Pires Barbosa. O Estado como Agente Facilitador da Indústria NavalMilitar Canadense (2010-2018). 2020. Dissertação (Mestrado em Estudos Marítimos) Escola de Guerra Naval, Rio de Janeiro, 2020a.

BARRETO, Jéssica Pires Barbosa. Uma Avaliação dos Sistemas de Aquisição de Defesa Canadense e Sueco em Perspectiva Comparada. 2020. Dissertação (Mestrado em Estudos Estratégicos da Defesa e da Segurança) - Universidade Federal Fluminense, Rio de Janeiro, 2020b.

BOWERING, Ken. National Shipbuilding: Where we are and where we're headed. Canadian Naval Review, v. 8, n. 2, 2012, p. 19-23. Disponível em: https://www.aph.gov. au/DocumentStore.ashx?id=559e01e3-5104-4d61-8dba-e020be183c75. Acesso em: 07 jul. 2020.

CANADA. Departament Of National Defence. Canada First Defence Strategy. 2008. Disponível em http: //www.forces.gc.ca/assets/FORCES_Internet/docs/en/about/CFDSSDCD-eng.pdf. Acesso em: 15 mai. 2020.

CANADA. Department of National Defence. White Paper on Defence. 1964. Disponível em: http://publications.gc.ca/collections/collection_2012/dn-nd/D3-6-1964-eng.pdf. Acesso em: 03 mar 2020.

CANADA. Public Services and Procurement Canada. About the National Shipbuilding Strategy. 2010. Disponível em: https:/www.tpsgc-pwgsc.gc.ca/app-acq/amd-dp/mer-sea/ sncn-nss/apropos-about-eng.html. Acesso em: 12 mar. 2020.

CANADA. Public Services and Procurement Canada. Canada announces next step toward adding third strategic partner under National Shipbuilding Strategy. 2019a. Disponível: $\quad$ https://www.canada.ca/en/public-services-procurement/news/2019/12/ canada-announces-next-step-toward-adding-third-strategic-partner-under-nationalshipbuilding-strategy.html. Acesso em: 02 fev. 2020.

CANADA. Public Services and Procurement. National Shipbuilding Strategy: February 2012 to December 2015 status report. 2016. Disponível em: https://www.tpsgc-pwgsc. gc.ca/app-acq/amd-dp/documents/rapport-report-eng.pdf. Acesso em: 01 fev. 2020.

CANADA. Public Services and Procurement Canada. National Shipbuilding Strategy: 2016 Annual Report. 2017b. Disponível em: https://www.tpsgc-pwgsc.gc.ca/app-acq/ amd-dp/mer-sea/sncn-nss/rapport-report-2016-eng.html. Acesso em: 02 fev. 2020.

CANADA. Public Services and Procurement Canada. National Shipbuilding Strategy: 2017 Annual Report. 2018. Disponível em: https://www.tpsgc-pwgsc.gc.ca/app-acq/ amd-dp/documents/rapport-report-2017C-eng.pdf. Acesso em: 09 fev. 2020. 
CANADA. Public Services and Procurement Canada. Canada's National Shipbuilding Strategy: 2018 Annual Report. 2019c. Disponível em: https://www.tpsgc-pwgsc.gc.ca/ app-acq/amd-dp/documents/rapport-report-2018C-eng.pdf. Acesso em: 09 fev. 2020.

CANADA. Public Services and Procurement Canada. Canada's National Shipbuilding Strategy: 2019 Annual Report. 2020. Disponível em: https:/www.tpsgc-pwgsc.gc.ca/appacq/amd-dp/mer-sea/sncn-nss/rapport-report-2019-eng.html. Acesso em: 15 fev. 2020.

CANADA. Public Services and Procurement. Phases of the National Shipbuilding Strategy. 2017a. Disponível em: https://www.tpsgc-pwgsc.gc.ca/app-acq/amd-dp/mersea/sncn-nss/phases-eng.html. Acesso em: 02 fev. 2020.

CANADA. Statistics Canada. Canadian Industry Statistics. 2019b. Disponível em https:// www.ic.gc.ca/app/scr/app/cis/search-recherche?lang=eng. Acesso em 10 fev. 2020.

COLLINS, Jeffrey F. Overcoming 'Boom and Bust'? Analyzing National Shipbuilding Plans in Canada and Australia. Calgary: Canadian Global Affairs Institute, 2019. Disponível em: https://www.cgai.ca/overcoming_boom_and_bust_analyzing_national_ shipbuilding_plans_in_canada_and_australia. Acesso em: 20 jun. 2020.

NOSSAL, Kim Richard. Charlie Foxtrot: Fixing defence procurement in Canada. A J. Patrick Boyer Book, 2016.

PLAMONDON, Aaron. The Politics of Procurement: Military Acquisition in Canada and the Sea King Helicopter. Ubc Pres, 2010.

SHOUTE, Ghin Mang. The National Shipbuilding Procurement Strategy: Securing Canada's Future Naval Shipbuilding Industry and Maritime Sovereignty. Dissertação (Mestrado em Políticas Públicas) - University Of Calgary, Calgary, 2015. Disponível em: $\quad$ https://prism.ucalgary.ca/bitstream/handle/1880/51681/Shoute\%2c\%20Ghin. pdf? sequence=1\&isAllowed=y. Acesso em: 10 mai. 2020.

SOLOMON, Binyam; PENNEY, Christopher. Canadian Defence Industrial Base. In: HARTLEY, Keith; BELIN, Jean (ed.). The Economics of the Global Defence Industry. Nova Iorque: Routeledge Studies in Defence and Peace Economics, 2020. pp. 437-461.

THE CONFERENCE BOARD OF CANADA. The Economic Impact of Canada's Arctic and Offshore Patrol Ship Program. Ottawa: 2018. Disponível em: https://www. conferenceboard.ca/temp/6fbfb58c-3370-4297-a439-31f331104351/9299_Eco-ImpactAOPS_BR.pdf. Acesso em: 15 mar. 2020.

VEDUNG, Evert. Six Models of Evaluation. In: ARARAL JR, Eduardo et al. Routledge Handbook of Public Policy. Londres: Routledge, 2013, pp. 387-400.

WILSON, J. K. The Politics and Economics of Shipbuilding in Canada: Lessons for Naval Planning? Dissertação (Mestrado em Estudos de Defesa) - Canadian Forces College, Kingston, 2009. Disponível em: https:/www.cfc.forces.gc.ca/259/290/295/286/wilson. pdf. Acesso em: 17 mar. 2020. 


\section{Notas}

1 O artigo foi redigido por Jéssica Pires Barbosa Barreto, resultando de pesquisa conduzida no âmbito do mestrado em Estudos Marítimos da Escola de Guerra Naval (PPGEM/EGN). Thauan Santos orientou-o conceitualmente e revisou-o.

2 Mestranda e pesquisadora do Grupo de Pesquisa Geopolítica Corrente (Geocorrente, no Núcleo de Avaliação da Conjuntura da Escola de Guerra Naval (EGN), Rio de Janeiro, Rio de Janeiro, Brasil. Email: barretojessicapb@gmail.com.

3 Professor Doutor do Programa de Pós-Graduação em Estudos Estratégicos da Escola de Guerra Naval (EGN), Rio de Janeiro, Rio de Janeiro, Brasil. Email: santos.thauan@gmail.com.

4 Zona Econômica Exclusiva (ZEE) é a área em que o país tem prioridade para exploração dos recursos naturais. Ela se estende até 200 milhas náuticas. Disponível em https://www.oeco.org.br/dicionarioambiental/29053-o-que-e-a-zona-economica-exclusiva/. Acesso em 12 jan. 2020.

5 O Imaginário de Segurança de uma sociedade condiz com a forma como a maior parte da população enxerga a localização do seu país dentro do contexto da política mundial; e isso molda suas expectativas políticas. Entretanto, essa concepção sobre o seu país no cenário internacional não necessariamente é condizendo com a realidade, sendo fruto de uma imaginação coletiva (NOSSAL, 2016).

6 A Solicitação de Interesse (SOI) consiste num período em que as empresas declararam seu interesse em participar da competição pelo contrato de aquisição. A partir disso, o governou criou uma lista cinco estaleiros que efetivamente participariam da competição pelos projetos de construção de grandes embarcações. Essa etapa não é uma constante nos processos de aquisição do Canadá (SHOUTE, 2015).

7 A Solicitação de Propostas (RFP) é abrangida no estágio de definição das aquisições de defesa do Canadá. A partir da aprovação do projeto por todos os departamentos envolvidos, em especial o Treasury Board, o DND passa a trabalhar no projeto de implementação da opção escolhida para aquisição lançando uma RFP para que a indústria envie propostas para o programa. Uma dessas propostas será selecionada como a ganhadora do projeto ou a RFP pode ser cancelada se nenhuma proposta enviada for dentro das possibilidades esperadas pelo escritório do DND (BARRETO, 2020b).

8 O Dólar Canadense é identificado ao longo do artigo por C\$ ou apenas \$. 